\title{
Quantum shifts in the genetic control of a colour polymorphism in Theridion grallator (Araneae: Theridiidae), the Hawaiian happy- face spider
}

\author{
G. S. OXFORD* \& R. G. GILLESPIE $\dagger$ \\ Department of Biology, University of York, PO Box 373, York YO1 5YW, U.K. and Center for Conservation Research \\ and Training, University of Hawaii, 3050 Maile Way, Gilmore 310, Honolulu, HI 96822, U.S.A.
}

\begin{abstract}
Theridion grallator, the Hawaiian happy-face spider, endemic to four islands in the Hawaiian archipelago, exhibits an exuberant colour and pattern polymorphism involving both the carapace and opisthosoma (abdomen). Previous work has shown that on Maui (and probably on Moloka'i as well) all colour morphs act as if they are determined by alleles at one autosomal locus (although linked loci cannot be excluded) and all morphs are expressed equally in males and females. Here we demonstrate that on Hawai'i, the youngest island, Yellow and Red front morphs seem to be controlled by a single allele, sex-limited in expression, such that females are Yellow and males Red front. Red blob and Red ring form a similar pair of morphs, again apparently controlled by one allele, with Red blob confined to females, Red ring to males. Morphs Red front + back and Black ring are not sex-limited. Evidence from one brood indicates that two unlinked loci are involved in determining the colour polymorphism on Hawai' $i$. At least the sex-limitation of Yellow and Red front is shown to be island-wide and suggests that the quantum shifts in the genetic control of the polymorphism among islands probably trace their origins to the founding event when T. grallator colonized Hawai'i from Maui.
\end{abstract}

Keywords: colour polymorphism, founder effect, genetic drift, Hawaii, sex-limitation, spider, Theridion grallator.

\section{Introduction}

Islands have always attracted students of evolution because they contain discrete populations of organisms isolated to greater or lesser extents from those on the mainland. Under such conditions evolutionary novelties may arise, and populations may differentiate and sometimes proliferate into many species. These processes are particularly marked on isolated oceanic archipelagos that have never formed part of a continental land mass, and in many of which new islands and novel habitats are constantly being created as a result of volcanic activity. The Hawaiian islands constitute the most isolated archipelago in the world (Clague \& Dalrymple, 1987), so it is not surprising that many of the best understood examples of rampant speciation involve Hawaiian taxa. Almost all of the native species are endemic to

*Correspondence. the archipelago, and many are unique to individual islands (Simon, 1987; Vitousek et al., 1987; Gagne, 1988). One feature which has probably been instrumental in at least initiating genetic differentiation within species is the low number of founding individuals involved in the establishment of populations on recently emerged islands. The depauparate genetic variation expected in founding populations, coupled with genetic drift in subsequent generations while population sizes remain small, may lead to considerable differences between the nature and variability of ancestral and newly established gene pools (Mayr, 1954; Carson \& Templeton, 1984; Coates, 1992). Selective pressures may also be different because the environment experienced by the founding population is unlikely to be identical to that of the area of original occupation. These circumstances, in which genetic drift and selection interact, may promote significant character shifts (Carson, 1990). Furthermore, it has recently been 
suggested that under the conditions experienced by founding populations, activation of transposable elements may occur leading to increased rates of mutation and other genetic effects (e.g. McDonald, 1989, 1995; Li \& Graur, 1992).

A number of studies have investigated genetic variation within populations of a species, and between closely related species, on the Hawaiian islands (see Wagner \& Funk, 1995). In particular for the Hawaiian Drosophilidae, a vast body of data exists on chromosome rearrangements (e.g. Carson, 1983, 1987), isozyme variation (e.g. Carson \& Johnson, 1975) and molecular markers (e.g. DeSalle \& Hunt, 1987; DeSalle \& Templeton, 1988; DeSalle, 1995). In a few cases, the broad function of some character divergence is known (e.g. sexually selected traits in some Hawaiian Drosophila species). However, even in this intensively studied group, the association between genetic changes and morphological, ecological and behavioural shifts is unclear (Kaneshiro \& Boake, 1987; Kaneshiro, 1988). We have found a unique system in which founder events can be associated with changes in a set of highly variable characters with a known, simple mode of inheritance and for which an adaptive function can be inferred. The organism concerned is Theridion grallator (Araneae: Theridiidae), the Hawaiian happy-face spider, which is endemic to four of the islands (O'ahu, Maui, Moloka'i and Hawai'i) and exhibits an exuberant colour polymorphism in all populations (Gon, 1985; Gillespie \& Tabashnik, 1989, 1990; Oxford \& Gillespie, 1996).

In an earlier paper (Oxford \& Gillespie, 1996), we identified and analysed genetically 11 colour morphs from East Maui (see also Gillespie \& Tabashnik, 1989) as well as more limited material from West Maui and Moloka'i. We demonstrated that the polymorphism is controlled by alleles at what appears to be a single, major locus with no sexual bias in the expression of morphs. In general, within the patterned morphs, dominance is determined by the area of pigmentation controlled by one allele being superimposed on that controlled by another; the unpatterned translucent Yellow morph is bottom recessive. An exception to this general rule of dominance is provided by the White morph, produced by a massive deposit of an excretory product, guanine, below the hypodermis. The White morph is dominant to virtually all red- and black-pigmented patterned morphs. Within a recognized colour morph there are submorphs which vary in the precise disposition of pigments and these too seem to segregate in broods as if they are allelic.

The Hawaiian happy-face spider populations studied so far have been on relatively old islands; Moloka'i (1.76 Myr old), West Maui (1.32 Myr) and East Maui (0.75 Myr). Theridion grallator also occurs on the youngest island, Hawai'i, different parts of which range in age from 0 to $0.43 \mathrm{Myr}$ (it is still in the process of formation). The populations on Hawai'i were almost certainly established from those on Maui, the next island up the chain and some $50 \mathrm{~km}$ away. It is of interest therefore to determine whether the genetic control of the colour polymorphism on Hawai'i conforms to that on Maui, as outlined above. Previous work has hinted that there may be differences in the nature of this polymorphism among islands; Stamps \& Gon (1983) and Gon (1985) suggested that there may be a sexual bias in the distribution of colour morphs on Hawai' $i$, whereas Gillespie \& Tabashnik (1989) and Oxford \& Gillespie (1996) found no such bias on the Greater Maui island complex.

\section{Materials and methods}

Spiders were collected during 1993 and 1994 from three populations on Hawai'i island occupying different volcanoes: (i) Kohala (oldest volcano, $0.43 \mathrm{Myr}$ ), Kahua Ranch, altitude $1152 \mathrm{~m}$; (ii) saddle between Mauna Kea (0.38 Myr) and Mauna Loa (0-0.4 Myr), Kipuka 8, Saddle Road, altitude $1600 \mathrm{~m}$; and (iii) Kilauea (0-0.4 Myr), Thurston, Volcanoes National Park, altitude $1190 \mathrm{~m}$. Spiders were found by searching the undersides of leaves of a variety of native plant species including Broussaisia, Clermontia, Coprosma, Ilex, Metrosideros and Pelea. Genetic information was gathered from two sources, wild-mated females and formal matings set up in the laboratory with virgin females and known males. Methods for establishing laboratory matings and the rearing of broods have been described elsewhere (Oxford \& Gillespie, 1996). Progeny were scored at several stages during their development and the sexes separated when males became apparent by their swollen pedipalps in the penultimate instar. Because of mortality, which varied greatly from one brood to the next, more individuals are scored for colour morphs than are scored for sex.

\section{Results \\ Genetics of opisthosomal morphs - Thurston population}

The majority of opisthosomal morphs found in the Hawaiian populations can readily be categorized according to the scheme used for Maui (plate 1 of 
Oxford \& Gillespie, 1996). Data from present laboratory crosses and from wild-mated females are shown in Tables 1 and 2, respectively. Unlike Maui populations, in which Yellow (unpatterned) is bottom recessive in both males and females, wildmated Yellow females from Thurston produced progeny in which all females identified were Yellow and all males Red front (Table 2, mating no. 16). This phenomenon is consistent across all Thurston matings, both in the laboratory (Table 1, nos 1-7) and in the wild (Table 2, nos 16-20): females are always Yellow and males always Red front unless a more dominant pattern is present.

The association between colour morph and sex could be attributed either to sex linkage or to sex limitation of the Red front and Yellow determinants. Sex linkage is unlikely for two reasons. First, information from Maui populations suggests that the allele controlling the Red front morph should be dominant to the unpatterned Yellow morph (Oxford \& Gillespie, 1996). The chromosomal sex-determining mechanism in all theridiids examined to date (and in almost all spiders) is XXO (male) and XXXX (female) (e.g. Kageyama \& Seto, 1979; Tugmon et al., 1990), which act essentially as an XO, XX system (White, 1973). If the frequency of the Red front allele is $p$ then, assuming a Hardy-Weinberg equilibrium, the frequency of the Red front phenotype in males should also be $p$, whereas in females it should be $p(2-p)$. Thus the expected frequency of this morph will always be higher in females for all $p<1$. Of course, the dominance of the morphs might not be the same on the two islands. A second argument, independent of dominance relationships, is that sex linkage affects the proportions of morphs in the sexes, not their occurrence. Yet here we observe an absolute association between particular colour morphs and sex. A more likely explanation for the association between colour morph and sex is that both morphs are controlled by one allele, sex-limited in its expression, or a system producing identical results.

Red ring and Red blob form another pair of sex-limited morphs restricted to males and females, respectively. A wild-mated Red front + back (no. 19, Table 2) produced a Red blob female and five Red ring males, as well as five Yellow females and four Red front + back males (the apparent association of the latter morph with sex is an artifact of sample size: see below). Mating no. 20, the female of which was not captured in the field, produced a small number of young but with a similar distribution of sex-associated morphs. The relationship between Red ring and Red blob was investigated further in formal matings involving offspring from these two broods test-crossed to either Red front males or Yellow females (nos 3, 4, 6 and 7, Table 1). In all five crosses, whether using Red ring males or Red blob females, all the male progeny were Red ring and all the females Red blob. The fact that either parental morph can give rise to both in the offspring suggests that here too, the patterns are a result of sex-limited expressions of effectively a single allele. In contrast to the two pairs of morphs discussed above, Red front + back segregates equally in males and females (nos 4-7, Table 1; nos 18 and 20, Table 2), as it does on Maui.

Mating no. 5 (Table 1), between a Red front + back female and a Red front male yielded two broods which are shown separately in Table 1 because morph frequencies are heterogeneous. The second brood showed a significant excess of Red front + back which appeared to fall into two distinct developmental phenotypes. Approximately half the progeny in this class developed the anterior and posterior red pigment patches, and associated guanine (see Oxford \& Gillespie, 1996), in tandem, whereas the other half deposited the anterior patch at a much slower rate. One female had no trace of any pigment or guanine in the anterior position on reaching maturity, and may represent an extreme case of differential pigment/guanine synthesis in the two regions. Alternatively, it could represent a rare recombination event between closely linked loci (Oxford \& Gillespie, 1996). Differential appearance of pattern elements was not recorded in Red front + back progeny from the first brood, but it may have been present.

Unfortunately, rather few of the Thurston matings provided any conclusive information on whether morphs are determined by alleles at the same locus. Crosses nos 3, 4, 6 and 7 (Table 1) derive from offspring of wild-mated females (nos 19 and 20, Table 2). In three of these crosses progeny segregated for Red blob/Red ring and Red front + back (nos 4, 6 and 7, Table 1), and in two for Red blob/ Red ring and Yellow/Red front (no. 3, Table 1). The former three show that Red front + back segregates with Red blob/Red ring in a manner consistent with them being determined by alleles at one locus. Cross no. 3 (Table 1) suggests that Red front/Yellow could either be allelic to Red blob/Red ring, or homozygous at an entirely separate locus. The dominance hierarchy of morphs (Fig. 1a) conforms to the situation found in Maui and elsewhere (Oxford \& Gillespie, 1996), namely phenotypes are those expected if constituent patterns are simply superimposed one upon the other. Here, however, Yellow and Red 


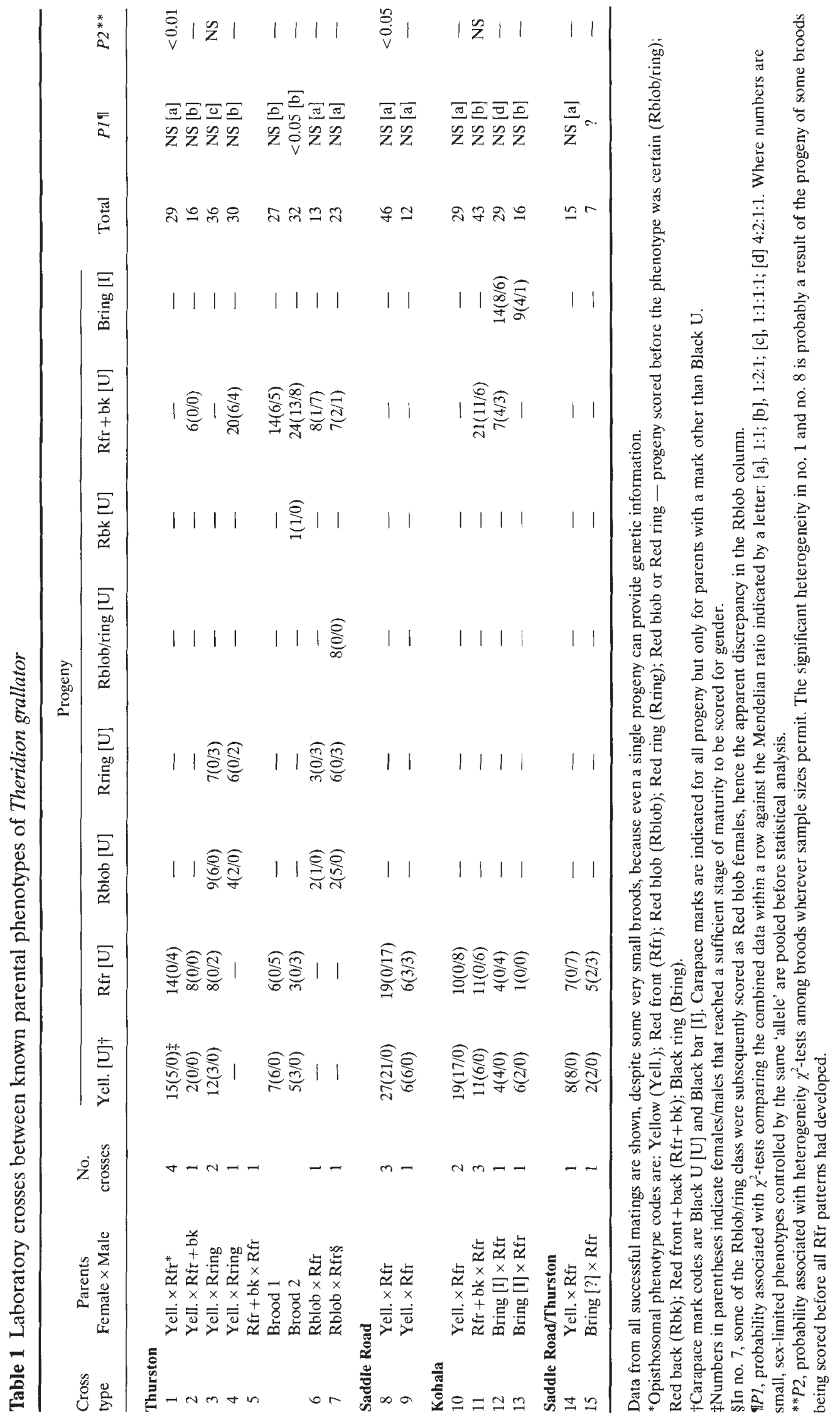

(c) The Genetical Society of Great Britain, Heredity, 76, 249-256. 
Table 2 Progeny from wild-mated females of Theridion grallator

\begin{tabular}{|c|c|c|c|c|c|c|c|c|c|c|}
\hline \multirow{2}{*}{$\begin{array}{l}\text { Cross } \\
\text { type }\end{array}$} & \multirow{2}{*}{$\begin{array}{l}\text { Female } \\
\text { parent }\end{array}$} & \multirow{2}{*}{$\begin{array}{c}\text { No. } \\
\text { crosses }\end{array}$} & \multicolumn{5}{|c|}{ Progeny } & \multirow[b]{2}{*}{ Total } & \multirow[b]{2}{*}{$P 1$} & \multirow[b]{2}{*}{$P 2$} \\
\hline & & & Yell. [U] & Rfr [U] & Rblob [U] & Rring [U] & $\mathrm{Rfr}+\mathrm{bk}[\mathrm{U}]$ & & & \\
\hline \multicolumn{11}{|c|}{1993 Thurston } \\
\hline 16 & Yell. & 8 & $76(33 / 0)$ & $80(0 / 77)$ & - & - & - & 156 & NS [a] & NS \\
\hline 17 & Yell. & 1 & $6(6 / 0)$ & $5(0 / 5)$ & - & - & - & 11 & NS [a] & - \\
\hline 20 & $?$ & 1 & $1(1 / 0)$ & $1(0 / 1)$ & $3(2 / 0)$ & $1(0 / 1)$ & $3(1 / 2)$ & 8 & - & - \\
\hline \multicolumn{11}{|c|}{1994 Saddle Road } \\
\hline 21 & Yell. & 1 & $3(3 / 0)$ & $1(0 / 1)$ & - & $1(0 / 1)$ & - & 5 & - & - \\
\hline
\end{tabular}

Explanations of phenotype nomenclature and column headings can be found in the legend to Table 1.

(a)

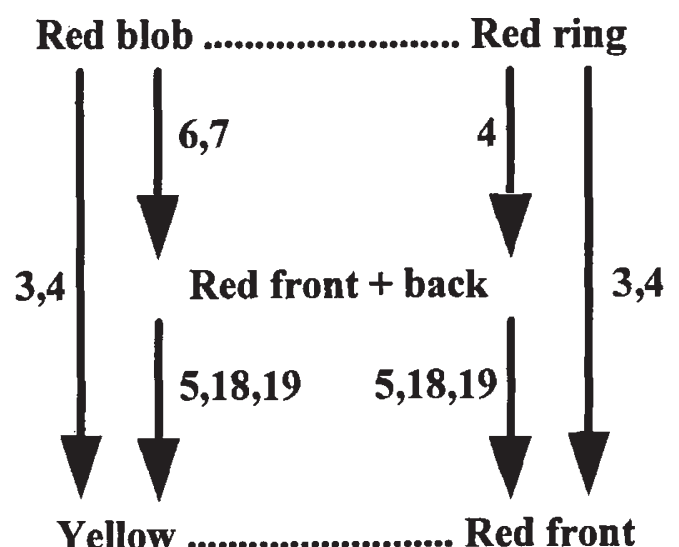

(b)

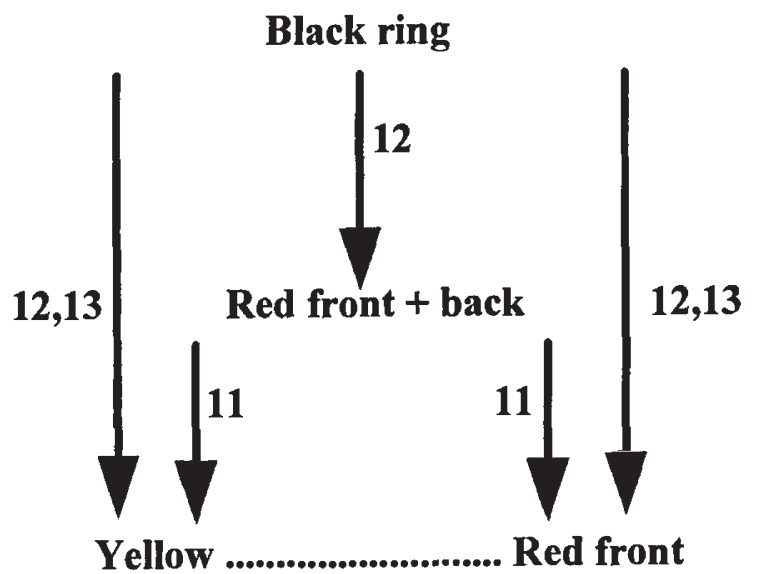

(C) The Genetical Society of Great Britain, Heredity, 76, 249-256. front are bottom recessive in females and males, respectively, rather than Yellow being the universal recessive.

\section{Genetics of opisthosomal morphs - Saddle Road and Kohala populations}

Of the 13 formal matings set up within and between the Kohala and Saddle Road populations, 11 showed the complete sex limitation of Yellow and Red front characteristic of the Thurston site (nos 8 and $10-14$, Table 1), as did the brood of the single wild-mated female, no. 21 (Table 2). Clearly this phenomenon is island-wide. In two broods from Saddle Road mothers, a number of Red front females appeared (nos 9 and 15, Table 1). The Red front + back morph appears equally in males and females (nos 11 and 12, Table 1), as does Black ring (nos 12 and 13, Table 1). The Black ring phenotype from the Kohala population differs slightly from that shown in Plate 1e of Oxford \& Gillespie (1996) in that the anterior portion of the ring is wider and contains an area of red pigment. The dominance hierarchy is shown in Fig. 1b. No matings were set up involving Red blob or Red ring morphs but one Red ring male appeared in the offspring of a wild-

Fig. 1 Summary diagram of the dominance relationships among the patterned morphs of Theridion grallator. (a) Thurston population; (b) Kohala population. Numbers refer to particular crosses (Tables 1 and 2) and arrows link pairs of morphs showing the direction of dominance. The morph at the arrowhead is recessive, e.g. Red ring is dominant to Red front. 
mated Yellow female from Saddle Road (no. 21, Table 2).

One cross (no. 12, Table 1) provides information on allelism among morphs and indicates clearly that the opisthosomal polymorphism, at least in the Kohala population, must involve more than one locus. The mating, between a Black ring female and a Red front male, yielded four classes of progeny: Black ring, Red front + back, Red front and Yellow. Red front + back is shown above to be dominant to Yellow/Red front, so the allele for this morph must have been carried by the female, as must the Black ring allele. If these two morphs are controlled by alleles at the same locus one would expect a 1:1 ratio of Black ring and Red front + back in the progeny. The fact that Yellow and Red front also segregated shows that the female must have been carrying the determinant of these bottom recessive characters as well. The simplest hypothesis is that Red front + back and Black ring are coded for by alleles at two different loci and that the female parent was heterozygous at both for the pattern allele and a bottom recessive allele. If the loci are unlinked and one assumes a 1:1 sex ratio, the expected offspring phenotypes would be Black ring:Red front + back: Red front:Yellow in a 4:2:1:1 ratio. The data fit this expectation extremely well (no. 12, Table 1).

\section{Genetics of carapace patterns}

As on Maui, the Black U carapace mark in Hawai' $i$ populations is associated with the majority of opisthosomal colour morphs. Also consistent with previous work (Oxford \& Gillespie, 1996) is the fact that the Black bar carapace pattern cosegregates with the Black ring phenotype (nos 12 and 13, Table 1). Both matings suggest that Black bar is dominant to Black $\mathrm{U}$, and are not inconsistent with the two patterns being controlled by alleles at one locus, as was shown to be the case on Maui.

\section{Discussion}

The opisthosomal colour morphs identified so far on Hawai'i are in appearance almost identical to their counterparts in populations on Maui. In terms of their genetics, however, there are two fundamental differences: (i) on Maui only one locus has been identified (Oxford \& Gillespie, 1996) whereas on Hawai'i at least two unlinked loci are involved; (ii) on Maui all morphs are individually determined by alleles (Oxford \& Gillespie, 1996) but on Hawai'i two pairs of morphs, Yellow and Red front, and
Red blob and Red ring, act as if the members of each pair are determined by just one allele with differential expression in males and females. These differences presumably arose very early on during the colonization of Hawai'i from Maui because, for the sex limitation of Red front and Yellow at least, the phenomenon is island-wide. It is possible therefore that the apparent change in the number of loci involved, and the sex-limitation of certain colour morphs, are manifestations of the same genetic event(s) that occurred during the founding episode. Several authors have shown, both theoretically and in laboratory experiments, that alterations in the genetic environment of small founder populations can lead to increased levels of additive genetic variance for biometrical traits (e.g. Goodnight, 1987, 1988; Bryant et al., 1990; Carson, 1990; Bryant \& Meffert, 1993). McDonald (1989, 1995) has also suggested that in circumstances such as these, there may be activation of mobile genetic elements. These could affect major gene loci by inducing changes in levels of gene expression, promoting gross genomic rearrangements (e.g. duplication, inversion and translocation) and increasing mutation rates $(\mathrm{Li} \&$ Graur, 1992).

With regard to point (i) above, it is important to emphasize that the demonstration of a single locus on Maui is not absolutely conclusive. We showed that Black ring was allelic to Red ring and that both were allelic to the bottom recessive, Yellow (Oxford \& Gillespie, 1996). The other patterned morphs are allelic inter se and to Yellow. The Yellow morph therefore acted as a link between these two sets of patterned morphs. This is consistent with the hypothesis that all are determined at a single locus, but it could also be the case that the two sets are controlled by alleles at different loci with each locus possessing what is effectively a 'null' (Yellow) allele. Further study is clearly necessary but results to date suggest that the disposition of alleles and loci on Maui and on Hawai'i are different.

Sex limitation is relatively common in spiders (Oxford \& Gillespie, in preparation) and Enoplognatha ovata (Theridiidae), the candy-stripe spider, presents in some respects a situation analogous to that described here. In $E$. ovata there are three opisthosomal colour morphs, plain yellow (form lineata), yellow with two dorso-lateral carmine stripes (form redimita) and yellow with a solid shield of carmine on the dorsal surface (form ovata) (plate 1 of Oxford, 1983), determined by three alleles at one autosomal locus. The morphs show a dominance hierarchy with lineata bottom recessive and ovata top dominant. The red pigmentation of redimita and 
ovata morphs is deposited either during the third or fourth instars, or after the spider has moulted to maturity (Hippa \& Oksala, 1979; Oxford, 1983, 1985). In Britain, only the redimita morph can develop at both stages, ovata always appearing early in development. Where redimita develops early, morph frequencies are the same in males and females whereas late-developing redimita is manifest only in females, males remaining plain yellow although they can be shown to be carrying the normally dominant redimita allele. Several models of the genetical control of this system have been advanced (Hippa \& Oksala, 1979; Oxford, 1983), the most parsimonious being that the colour locus is tightly linked to a polymorphic regulatory locus or control sequence which is cis-acting on its adjacent colour allele, and that the 'late' regulatory allele requires the hormonal environment of a mature female for activation (Oxford, 1983).

A similar situation could have arisen in the Hawai'i populations of $T$. grallator as a result of a mutation at a regulatory locus closely linked to that containing the major colour alleles or, perhaps more likely, by a translocation in which the colour locus was inserted next to such a regulatory sequence. In T. grallator one would have to postulate that the Red front allele is activated in the hormonal milieu of males but not of females; the latter would retain the 'null' pattern giving the Yellow morph. If this is the case, the genetical system must differ in two ways from that in E. ovata. First, the dominant morph is suppressed in females rather than in males, and secondly, a mature male hormonal environment is not required for expression because Red front in males usually develops in immature instars. The situation is complicated by the fact that for the Red blob/Red ring pair the control of expression has to be reversed; the full pattern seems to be manifest in females rather than males. The presence of some Red front females in two broods (nos 9 and 15, Table 1) might represent a loss of suppression possibly as a result of mutation in the hormonally controlled regulatory sequence.

Morphs Red front + back and Black ring are found equally in males and females. The former acts as if it is allelic to Red blob/Red ring (and possibly also to Red front/Yellow), as it is in other populations. As pointed out before (Oxford \& Gillespie, 1996), the existence of Red front, Red back and the combined pattern, Red front + back, all apparently segregating as alleles, could suggest that more than one tightly linked locus is involved. The segregation of two Red front + back phenotypes in cross no. 5 , in which the rate of development of the anterior pattern was either the same as or noticeable slower than the posterior component, also points to a degree of independence in the control of the pattern components. This is consistent with determination by separate genetic elements, as might be the appearance of a single Red back offspring. The Black ring allele is shown to reside at another, unlinked locus to Red front + back. On Maui, both appear to be allelic to Yellow, and possibly therefore to all other patterned morphs examined (Oxford \& Gillespie, 1996).

\section{Acknowledgements}

The work reported here was supported in Hawai'i by National Science Foundation Grant DEB 9207753 to R.G.G and G.S.O., and in York by Natural Environment Research Council Grant GR9/1530 to G.S.O. Additional support to enable G.S.O. to work in Hawai'i during 1993 is gratefully acknowledged from the British Ecological Society, the Royal Society, the Bonhote Bequest, the Percy Sladen Memorial Fund and the University of York. We thank Peter Follett, Roma Oxford, David Preston, George Roderick and An-Ming Tan for assistance in the field, and Patrick Conant, Linden Doescher, Kelvin Kanegawa and Bruce Tabashnik for supplying diamond-back moths, Drosophila grimshawi and D. melanogaster as prey. The late Keith Partridge provided essential logistical support in York. For assistance in gaining access to collecting sites we would like to thank Monty Richards (Kahua Ranch) and the National Parks Service (Thurston). Thanks also to Bill Mull and Sam Gon for discussion and two anonymous referees for helpful comments on the manuscript.

\section{References}

BRYANT, E. H. AND MEFFERT, L. M. 1993. The effect of serial founder-flush cycles on quantitative genetic variation in the housefly. Heredity, 70, 122-129.

BRYANT, E. H., MEFFERT, L. M. AND McCOMMAS, S. A. 1990. Fitness rebound in serially bottlenecked populations of the house fly. Am. Nat., 136, 542-549.

CARSON, H. L. 1983. Chromosomal sequences and interisland colonizations in Hawaiian Drosophila. Genetics, 193, 465-482.

CARSON, H. L. 1987. Tracing ancestry with chromosomal sequences. Trends Ecol. Evol., 2, 203-207.

CARSON, H. L. 1990. Increased genetic variance after a population bottleneck. Trends Ecol. Evol., 5, 228-230.

CARSON, H. L. AND JOHNSON, w. E. 1975. Genetic variation in Hawaiian Drosophila I. Chromosome and allozyme 
polymorphism in $D$. setoimentum and $D$. ochrobasis from the island of Hawaii. Evolution, 29, 11-23.

CARSON, H. L. AND TEMPLETON, A. R. 1984. Genetic revolutions in relation to speciation phenomena: the founding of new populations. Ann. Rev. Ecol. Syst., 15, 97-131.

ClaGue, D. A. AND DALRYMPLE, G. B. 1987. The HawaiianEmperor volcanic chain, part 1, geologic evidence. In: Decker, R. W., Wright, T. L. and Stauffer, P. H. (eds) Volcanism in Hawaii, pp. 5-54. U.S. Geol. Surv. Prof. Pap. no. 1350, Washington, DC.

COATES, D. J. 1992. Genetic consequences of a bottleneck and spatial genetic structure in the triggerplant Stylidium coroniforme (Stylidiaceae). Heredity, 69, 512-520.

DESALLE, R. 1995. Molecular approaches to biogeographic analysis of Hawaiian Drosophilidae. In: Wagner, W. L. and Funk, V. A. (eds) Hawaiian Biogeography: Evolution on a Hot Spot Archipelago, pp. 72-89. Smithsonian Institution Press, Washington, DC.

DESALLE, R. AND HUNT, J. A. 1987. Molecular evolution of Hawaiian drosophilids. Trends Ecol. Evol., 2, 212-216.

DESALLE, R. AND TEMPLETON, A. R. 1988. Founder effects and the rate of mitochondrial DNA evolution in Hawaiian Drosophila. Evolution, 42, 1076-1084.

GAGNE, w. C. 1988. Conservation priorities in Hawaiian natural systems. Bioscience, 38, 264-271.

GILLESPIE, R. G. AND TABASHNIK, B. E. 1989. What makes a happy face? Determinants of colour pattern in the Hawaiian happy face spider Theridion grallator (Araneae, Theridiidae). Heredity, 62, 355-363.

GILLESPIE, R. G. AND TABASHNIK, B. E. 1990. Maintaining a happy face: stable colour polymorphism in the spider Theridion grallator (Araneae, Theridiidae). Heredity, 65, $67-74$.

GON, S. M. 1985. Comparative Behavioral Ecology of the Spider Theridion grallator (Simon) (Araneae: Theridiidae) in the Hawaiian Archipelago. Ph.D. Thesis, University of California, Davis, CA.

GOODNight, C. J. 1987. On the effect of founder events on epistatic genetic variance. Evolution, 41, 80-91.

GOODNighT, C. J. 1988. Epistasis and the effect of founder events on the additive genetic variance. Evolution, 42, $441-454$.

HIPPA, H. AND OKSALA, I. 1979. Colour polymorphism of Enoplognatha ovata (Clerck) (Araneae: Theridiidae) in western Europe. Hereditas, 90, 203-212.

Kageyama, A. AND seto, T. 1979. Chromosomes of seven species of Japanese theridiid spiders. Chromosome Inf. Serv., 27, 10-11.

KAINESHIRO, K. Y. 1988. Speciation in the Hawaiian Droso- phila. Bioscience, 38, 258-263.

KAINESHIRO, K. Y. AND BOAKE, C. R. B. 1987. Sexual selection and speciation: issues raised by Hawaiian drosophilids. Trends Ecol. Evol., 2, 207-212.

LI, W.-H. AND GRAUR, D. 1992. Fundamentals of Molecular Evolution. Sinauer Associates, Sunderland, MA.

MCDONALD, J. F. 1989. The potential evolutionary significance of retroviral-like transposable elements in peripheral populations. In: Fontdevila, A. (ed.) Evolutionary Biology of Transient Unstable Populations, pp. 190-205. Springer-Verlag, New York.

McDONALD, J. F. 1995. Transposable elements: possible catalysts of organismic evolution. Trends Ecol. Evol., 10, 123-126.

MAYR, E. 1954. Change in genetic environment and evolution. In: Huxley, J. S., Hardy, A. C. and Ford, E. B. (eds) Evolution as a Process, pp. 156-180. George Allen and Unwin, London.

OXFORD, G. s. 1983. Genetics of colour and its regulation during development in the spider Enoplognatha ovata (Clerck) (Araneae: Theridiidae). Heredity, 51, 621-634.

OXFORD, G. s. 1985. Geographical distribution of phenotypes regulating pigmentation in the spider Enoplognatha ovata (Clerck) (Araneae: Theridiidae). Heredity, 55, 37-45.

OXFORD, G. S. AND GILLESPIE, R. G. 1996. Genetics of a colour polymorphism in Theridion grallator (Araneae: Theridiidae), the Hawaiian happy-face spider, from Greater Maui. Heredity, 76, 238-248.

SiMON, C. 1987. Hawaiian evolutionary biology: an introduction. Trends. Ecol. Evol., 2, 175-178.

STAMPS, J. A. AND GON, S. M. 1983. Sex-biased pattern variation in the prey of birds. Ann. Rev. Ecol. Syst., 14, 231-253.

TUGMON, C. R., BROWN, J. D. AND HORNER, N. V. 1990. Karyotypes of seventeen USA spider species (Araneae, Araneidae, Gnaphosidae, Loxoscelidae, Lycosidae, Oxyopidae, Philodromidae, Salticidae and Theridiidae). J. Arachnol., 18, 41-48.

VITOUSEK, P. M., LOOPE, L. L. AND STONE, C. P. 1987. Introduced species in Hawaii: biological effects and opportunities for ecological research. Trends Ecol. Evol., 2, 224-227.

WAGNER, W. L. AND FUNK, V. A. (eds) 1995. Hawaiian Biogeography: Evolution on a Hot Spot Archipelago. Smithsonian Institution Press, Washington, DC.

white, M. J. D. 1973. Animal Cytology and Evolution, 3rd edn. Cambridge University Press, Cambridge. 